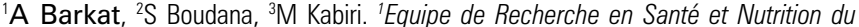
Couple Mère Enfant, Faculté de Médecine et de Pharmacie de Rabat, Université Souissi; ${ }^{2}$ Faculté de Médecine et de Pharmacie de Rabat; Université Souissi; ${ }^{3} C R E C E T$; Faculté de Médecine et de Pharmacie de Rabat, Rabat, Morocco

The objective: Evaluation of fetal and neonatal immediate impact of pregnancy hypertensive disease, and a comparison between the severity of gestational hypertensive disease and neonatal outcome. Materials and Methods This work was based on the analysis of the neonatology registers of the maternity service in Rabat's university hospital during 2010. we selected the newborns from mothers with gestational hypertension, and we clarified the evolutionary stage of this disease. A standardized form of farm has been established for this purpose.

Results 560 newborns meeted the analysis criteria, that is $3.69 \%$ of all newborns during this period. The average age of the parturients was $28 \pm 12$ years. Delivery has been advocated by Caesarean in $53.2 \%$ of cases, perinatal asphyxia was associated in $12.8 \%$ of cases. The prematurity rate was $16.8 \%$. The hyportrophy was observed in $44 \%$ and macrosomia in 3\% of cases. Fetal mortality was observed in $10.7 \%$ of cases.

The péeclampsie represents $28.5 \%$ of cases, and retroplacental hematoma which is the most frequent maternal complication was $9.1 \%$. Mortality and neonatal morbidity changes depending on maternal complications. Mortality and neonatal morbidity vary significantly according to maternal complications. In this study, the retroplacental hematoma, the helpp syndrome and eclampsia are responsible for a high rate of fetal mortality $(27.5 \%)$, neonatal mortality $(12 \%)$ and perinatal asphyxia (39.6\%) compared to preeclampsia and uncomplicated gestational hypertension.

Conclusion There is a clear correlation between the stage of the gestational hypertension evolution and the newborn's prognosis. The latter can be improved by a correct maternal prenatal monitoring.

\section{A COMPARATIVE STUDY OF KLIMEK AND BALLARD METHODS IN DETERMINING NEONATAL MATURITY IN IRAN}

doi:10.1136/archdischild-2012-302724.1274

R Saeedi, S Rahmani, S Loee. Mashhad University of Medical Sciences, Mashhad, Iran

Background and purpose: Severe prematurity, as the most important factor in premature neonatal mortality, is of paramount importance and accounts for 60-80 percent of neonatal mortality without abnormalities. Therefore, by defining the exact time of fetus maturity, complications and side effects could be predicted and best decisions could be made. Since the present methods are complicated, time-consuming and stressful for the neonates, researchers decided to compare the simple Klimek method with the New Ballard method. Methods and materials: This study is a descriptive cross-sectional research. Qualified neonates in a single group were examined for maturity by both Klimek and New Ballard methods. Neonate was examined by the first co-researcher with New Ballard method, and immediately examined by the second co-researcher with Klimek method. The second neonate was examined by the first co-researcher with Klimek method and then immediately by the second coresearcher with Ballard method. All 229 neonates were examined in this way. The examinations were done in the first 6-12 hours after birth. Analysis of data was conducted in SPSS, using Mann Whitney $U$ and Kappa Coefficient.

Results In $74.6 \%$ (171 cases) the same gestational age was obtained by both methods ( $p=0.664$ ). Also, determination of gestational age by Klimek method and LMP was not statistically different; and $75.9 \%$ (174 cases) the same gestational age was obtained by both methods ( $\mathrm{p}=0.943)$. In $51.5 \%$ (118 cases), both methods detected mature neonates $(\mathrm{K}=0.806)$.
Conclusion The simple Klimek Method is completely compatible with the New Ballard and LMP methods in determining neonatal maturity.

\section{THE NEURODEVELOPMENTAL ASSESSMENT OF VERY LOW BIRTH WEIGHT INFANTS AT 4-6 YEARS OF AGE AND THE RELATIONSHIP WITH RISK FACTORS}

doi:10.1136/archdischild-2012-302724.1275

'N Kavas, 'AE Arısoy, ${ }^{2 B}$ Kara, ${ }^{1} \mathrm{~A}$ Günlemez, ' $\mathrm{G}$ Türker, 'M Oruç, 'AS Gökalp. Neonatology; ${ }^{2}$ Pediatric Neurology, Kocaeli University Medical Faculty, Kocaeli, Turkey

The major and minor neurodevelopmental morbidities among premature infants become an important issue because of the increase in the number of surviving premature newborns, especially in the smaller gestational age group.

The aim of this study was to examine the neuromotor outcome of the premature newborns at 4-6 years of age born with very low birth weight and to investigate the risk factors associated with this outcome.

The present study was conducted in 70 very low birth weight children born during april 2004 and june 2007. The neuromotor status of 68 children were evaluated according to Touwen. The hospital records of the children were scanned for various risk factors.

Three cases were already diagnosed and followed as CP. The remaining 65 children did not meet the criteria for CP. According to Touwen examination 28 (\%41.2) children were considered as normal, 35 (\%51.5) had simple minor neurological dysfunction, 2 (\%2.9) had complex minor neurological dysfunction.

35 children with minor neurological dysfunction and 28 children with normal neuromotor status were compared for some risk factors. The children with minor neurological dysfunction had significantly lower Apgar score, their hosipitalization period was longer and the diagnosis rate of clinical (\%73.5; \%25) and culture proven sepsis (\%47.1; \%10.7) was higher in this group.

Sepsis was significantly associated with adverse neurological outcome. The prevention of neonatal sepsis in NICU's will increase the chance for healthy neurological development.

\section{GENOTYPIC EXPRESSION OF FADS2 IN PRETERM BABIES FED EXCLUSIVELY ON HUMAN MILK VERSUS FORMULA FED}

doi:10.1136/archdischild-2012-302724.1276

${ }^{1} \mathrm{AM}$ Abul-Fadl, ${ }^{2} \mathrm{NF}$ Al Husseini, ${ }^{2} \mathrm{AY}$ Idris. ${ }^{1}$ Pediatric; ${ }^{2}$ Biochemistry, Benha Faculty of Medicine, Cairo, Egypt

Background Exclusively breastfed premature babies have been shown to have higher intelligent quotient scores and superior cognitive development than those deprived of human milk. However the underlying cause has not been clearly defined.

Aim The aim of this study is to measure genetic expression of FADS2 gene responsible for cognition in babies exposed to different modes of feeding.

Methods Thirty preterm babies were studied for gene expression of FADS2 at birth and three months later. They were randomized into those supported to exclusively breastfeed (15) and those exposed to the normal routine of formula feeding practices in the neonatal intensive care units.

Findings There was no difference between gene expression between the groups at birth. However FADS2 expression was shown to be significantly higher in the breast fed groups at three months of age.

Conclusions Exposure of preterms to human milk potentates cognition through influencing transfer and/or maturation of genetic information responsible for cognition. 


\section{NEONATAL MORBIDITY AND MORTALITY IN EXTREMELY PRETERM SMALL FOR GESTATIONAL AGE INFANTS}

doi:10.1136/archdischild-2012-302724.1277

${ }^{1} \mathrm{~K}$ Itabashi, ${ }^{1 T}$ Yamakawa, ${ }^{2} \mathrm{~S}$ Kusuda, ${ }^{3} \mathrm{M}$ Fujimura. ${ }^{1}$ Pediatrics, Showa University School of Medicine; ${ }^{2}$ Tokyo Women's Medical University; Tokyo; ${ }^{3}$ Osaka Medical Center and Research Institute for Maternal and Child Health, Osaka, Japan

Background Neonatal mortality and morbidity in extremely preterm infants ( $<28$ weeks of gestation) have been extensively studied, but the risk added by intrauterine growth restriction remains controversial.

Aim To assess whether intrauterine growth restricted (small for gestational age, SGA) extremely preterm infants show a further increase in neonatal mortality and morbidity.

Methods The study included 9,888 singleton extremely preterm infants whose live birth was recorded at the Neonatal Research Network in Japan during 2003-2010. SGA was defined as birth weight at least 2SD below the mean for gestational age. The Risk of mortality and morbidity in the SGA group was evaluated by comparing outcomes for SGA against a non-SGA reference group.

Results Of the study subjects, 1,215 (12.3\%) were SGA. Controlling for gestational age, sex, parity and multiple gestation, SGA infants showed a higher mortality rate during NICU stay compared with reference group infants (odds ratio [OR]: 4.23, $\mathrm{p}<0.0001$ ). Severe neonatal asphyxia (OR: $1.89, \mathrm{p}<0.0001)$, RDS (OR: 1.33 , $\mathrm{p}<0.0001)$, chronic lung disease at 36 weeks' postmenstrual age (OR: 2.23, $\mathrm{p}<0.0001$ ), sepsis (OR: 1.95, $\mathrm{p}<0.0001$ ), necrotizing enterocolitis (OR: 1.93, p<0.0001), focal intestinal perforation (OR: $1.46, \mathrm{p}=0.011$ ) and congenital anomalies (OR: 2.66, $\mathrm{p}<0.0001)$ were significantly associated with SGA status.

Conclusion Extremely preterm SGA infants are associated with increased the risk of neonatal mortality and major morbidity. These results are important for obstetric counseling and decision making and treatment of extremely preterm infants.

\section{OUTCOME FOLLOWING FETAL PLEUROAMNIOTIC SHUNTING IN 114 LARGE HYDROTHORACES}

doi:10.1136/archdischild-2012-302724.1278

${ }^{1} \mathrm{E}$ Kelly, ${ }^{2} \mathrm{G}$ Seaward, ${ }^{2} \mathrm{R}$ Windrim, ${ }^{2} \mathrm{G}$ Ryan. ${ }^{1}$ Paediatrics; ${ }^{2}$ Obstetrics \& Gynecology, Mt Sinai Hospital, Toronto, ON, Canada

Introduction Untreated, fetal hydrothorax is associated with significant morbidity and a mortality rate of approximately $80-90 \%$.

Population 114 fetuses with isolated large pleural effusions underwent pleuroamniotic shunting at our perinatal centre. All had an extensive antenatal work-up including: detailed anatomy, echocardiogram, karyotype, infectious testing for CMV, Toxoplasmosis and Parvovirus. 84 were bilateral, 72 (63\%) were hydropic and 41 (36\%) had associated polyhydramnios,. Mean maternal age was 30.2 years, the mean gestation at diagnosis was 25 weeks and at shunting 27.6 weeks. 64 required bilateral shunts and, of unilateral, 27 were leftsided and 23 right-sided. 25 underwent simultaneous amnioreduction. The mean interval to delivery was $7 \mathrm{wks}$.

Results There were 15 (12.3\%) intrauterine deaths. 26 (23\%) neonatal deaths and $73(64.7 \%)$ survivors. Additional abnormalities including genetic, metabolic and neurological syndromes were identified antenatally in 8 cases and postnatally in 9 . Of 99 liveborn babies, $76(77 \%)$ delivered at our perinatal centre. Postnatally, 46 required ventilation, $38(50 \%)$ required chest tubes, of whom 19 $(26 \%)$ died. Of 73 survivors, 2 (3\%) were lost to follow-up, 4 (5.5\%) are $<4$ months of age, 10 (14\%) showed evidence of significant developmental delay, including 3 with Trisomy 21, and 1 had mild developmental delay. Fifty five (75\%) are developing normally.

Conclusion Fetal hydrothorax can be associated with a wide range of conditions, some of which may not be detectable antenatally.
Fetal therapy significantly improves perinatal outcome, although mortality remains high. On long term follow up, approximately $75 \%$ of survivors are developmentally normal.

\section{EARLY OUTCOMES FOLLOWING REFERRALS FOR THERAPEUTIC HYPOTHERMIA - A REGIONAL NEONATAL TRANSFER SERVICE PERSPECTIVE}

doi:10.1136/archdischild-2012-302724.1279

1.2PK Yajamanyam, ${ }^{2} \mathrm{~S}$ Mohinuddin. ${ }^{\top}$ Neonatal Unit, Birmingham Women's Hospital NHS Foundation Trust, Birmingham; ${ }^{2}$ Neonatal Transfer Service, Barts Health NHS Trust, London, UK

Background and Aims Therapeutic hypothermia $(\mathrm{TH})$ is now a standard of care for neonatal encephalopathy (NE). We have previously shown that referrals for $\mathrm{TH}$ in the London region have steadily increased since the publication of TOBY study but documentation of cooling criteria was poor (43\%) before transfer to cooling centres. In this study we audit referrals for $\mathrm{TH}$ following introduction of a structured proforma and the early outcomes of these babies.

Methodology Prospective audit of referrals for TH to a regional neonatal transfer service over a six-month period (May-October 2011). Audit registered with the Clinical Effectiveness unit of the NHS Trust. Following transfer, cooling centres was contacted to find out early outcomes: if infants received $\mathrm{TH}$ for 72 hours and outcome at 7 days.

Results 43 referrals for $\mathrm{TH}$ were received. The median Gestation was 40(35-42) weeks, Birth-weight 3.42(2.04-4.84) Kg. Of these 38 transfers were performed. Completed proforma was available in 21 cases. TOBY criteria A were recorded in $100 \%$ of cases and TOBY criteria B in $88 \%$. $8(21 \%)$ infants did not receive $\mathrm{TH}$ for 72 hours as assessed to not benefit from $\mathrm{TH}$ of which 3 died within 72 hours. At 7 days of age 5 were discharged home and remaining 30 were inpatients.

Conclusions Our audit shows that introduction of a structured proforma can improve documentation of cooling criteria and neurological examination. We recommend that any referral for $\mathrm{TH}$ is carefully selected to avoid unnecessary transfer of neonates who may not benefit from $\mathrm{TH}$.

\section{EFFECTS OF AMBIENT NOISE ON COCHLEAR FUNCTIONS IN NEWBORNS GRADUATED FROM NICU}

doi:10.1136/archdischild-2012-302724.1280

S Beken, E Önal, B Gündüz, Y Kemaloğlu, U Çakır, M Özden, I Karagöz, F Kulalı, i Hirfanoğlu, C Türkyılmaz, E Ergenekon, E Koç, Y Atalay. Gazi University Hospital, Ankara, Turkey

Background and Aim Neonatal Intensive Care Unit (NICU) is a noisy environment in which infants can be exposed to high noise levels. The aim of the study is to evaluate the adverse effects of noise on hearing and, neurological outcomes of NICU graduates at six months of age.

Methods Thirty two infants that had been admitted to Gazi University Hospital NICU and 25 healthy controls, were included in the study. Noise levels were recorded continously during hospitalization period. TEOAE, DPOAE and ABR tests were used to assess hearing. Neurological outcome was assessed with Bayley II Infant Development Scale.

Results The median period of noise exposure above $45 \mathrm{~dB}$, was $50.1 \%$ of the entire hospitalization period. Levels exceeding $45 \mathrm{~dB}$ were mostly below $124 \mathrm{~Hz}$. Major source of noise was traced back to the incubators. All patients passed the hearing screening tests before discharge. On the sixth month follow up; hospitalized infants had lower DPOAE SNR amplitudes $(\mathrm{dB})$ at five frequencies including 1001, 1501, 3003, 4004, $6006 \mathrm{~Hz}$ in both ears. DPOAE fail rates at $1001 \mathrm{~Hz}$ and $1501 \mathrm{~Hz}$ were higher in hospitalized infants 